\title{
meso-Antracenyl-BODIPY dyad as a new photocatalyst in ATRA reac- tions
}

\author{
Sara Abuhadba, ${ }^{1}$ Miu Tsuji, ${ }^{2}$ Tomoyasu Mani*,2 and Tatiana V. Esipova*,1 \\ ${ }^{1}$ Department of Chemistry and Biochemistry, Loyola University Chicago, Chicago, IL 60660, USA. Email: \\ tesipova@luc.edu \\ ${ }^{2}$ Department of Chemistry, University of Connecticut, Storrs, CT 06269-3060, USA. E-mail: tomo- \\ yasu.mani@uconn.edu
}

KEYWORDS: Donor-Acceptor dyad, BODIPY, triplet state, ATRA, photocatalysis

\begin{abstract}
We demonstrate that because of the efficient generation of triplet excited state under UV or visible-light irradiation, meso-antracenyl-BODIPY donor-acceptor dyad can catalyze ATRA reactions between bromomalonate and alkenes. This finding paves the way for the design and application of the new type of heavy atom-free organic chromophores for photocatalysis.
\end{abstract}

\section{INTRODUCTION}

In the past few decades, the field of photocatalysis attracted much attention among synthetic chemists. Photocatalysis, as a method of activation of organic molecules, relies on the electron or energy transfer between photoexcited catalysts and substrates, and allows bond formation and breakage under mild conditions. Though the most used photocatalysts - ruthenium or iridium polypyridyl complexes have already proved their efficiency in multiple reactions ${ }^{1-}$ 5 , their high cost, laborious synthesis, and generation of heavy-atom wastes prompted chemists towards the search and development of new photocatalytic systems ${ }^{6-15}$. Among them, there are several examples of application of metalfree organic chromophores as photocatalysts in the reactions of oxidation ${ }^{16-20}$, reductive dehalogenation ${ }^{21}, \mathrm{C}-\mathrm{C}$ bond formation ${ }^{22-26}$ and others ${ }^{27-30}$. For the majority of catalysts, either organometallic complexes or metal-free chromophores, the ability to form long-lived excited states has been postulated as a prerequisite for the efficient photocatalytic activity ${ }^{31,32}$. Within this context, we turned our attention to the recently reported orthogonal electron donor-acceptor (D-A) boron dipyrromethene (BODIPY)-based dyads ${ }^{33}$. In these dyads the BODIPY chromophores are usually substituted at the meso-position with another $\pi$-conjugated "dye", e. g. anthracene (Ant), so that the planes of BODIPY and the "dye" form an angle close to $90^{\circ}$ (Fig. 1a). The dyads possess long-lived triplet excited states of BODIPY, when selectively excited at either BODIPY or the "dye" unit of the dyad. Notably, in contrast to many other organic and organometallic compounds, the formation of the triplet excited states in "dye"-BODIPY dyads does not require the presence of heavy atoms in the structure of chromophores. In this case, the generation of the triplet excited state of BODIPY $\left(\mathrm{T}_{1}\right)$ proceeds through the initial formation of the charge-separated state $\left({ }^{1} \mathrm{CS}\right)$ within the dyad, where BODIPY unit usually serves as an electron acceptor, and the "dye" as a donor (Fig.

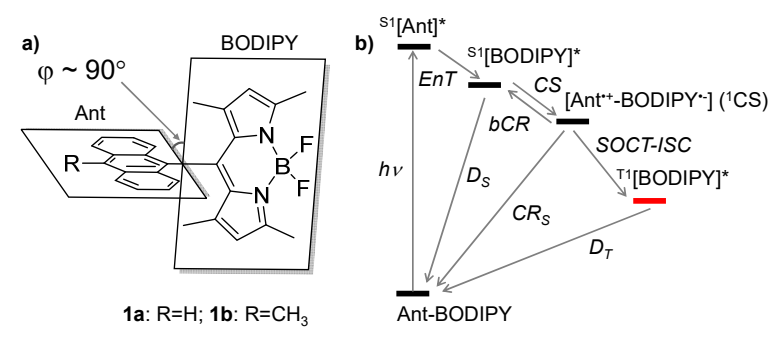

Figure 1. (a) Molecular structures and (b) Photophysical scheme of the catalysts. EnT = energy transfer; $\mathrm{CS}=$ charge separation; $\mathrm{bCR}=$ back charge recombination; $\mathrm{CR}_{\mathrm{S}}=$ singlet charge recombination; $\mathrm{D}_{\mathrm{S}}=$ singlet decay; $\mathrm{D}_{\mathrm{T}}=$ triplet decay.

1b). Importantly, the spin-forbidden ${ }^{1} \mathrm{CS} \rightarrow \mathrm{T}_{1}$ transition, termed spin-orbit charge-transfer intersystem crossing (SOCT-ISC) is favored when the molecular orbitals of the donor ("dye") and acceptor (BODIPY) are orthogonal, creating a large enough orbital angular momentum for the spin flip. ${ }^{34-36}$ The quantum yields of the triplet excited states formation can reach $90 \%$ and above in the dyads with the properly matching photophysical parameters of the BODIPY and the "dye" units (e. g., redox potentials, excitation energies, etc.). This trend of the "dye"-BODIPY dyads to the efficient formation of long-lived triplet excited states encouraged us to explore the possibility of their application as photocatalysts in chemical reactions.

\section{RESULTS AND DISCUSSION}

Among various types of chemical transformations, the $\mathrm{C}-\mathrm{C}$ bond formation seemed to us the most attractive, as it constitutes the fundamental basis for the creation of new organic frameworks. When choosing the reaction, we also considered the fact that the catalytic cycles should include the oxidation or reduction of the photoexcited catalyst by 
the substrate. While excited states of ruthenium or iridium complexes can be easily oxidized or reduced, the oxidation/reduction of the triplet excited state of BODIPY might be challenging due to the lower redox potentials. However, this issue can be overcome if a sacrificial reductant or oxidant is used to convert the excited state of the catalyst. Based on these considerations, we chose Atom Transfer Radical Addition (ATRA) as a model reaction to test the photocatalytic performance of "dye"-BODIPY dyad. Photoredox ATRA reactions between olefins and various halogen containing reagents have been thoroughly studied by Stepheson group ${ }^{37}$, using $\mathrm{Ru}(\mathrm{bpy})_{3}{ }^{2+}$ as photocatalyst and a wide range of sacrificial reductants from alkyl- and aryl-amino derivatives to sodium ascorbate. Moreover, recently it was shown, that diiodo-BODIPY in combination with sodium ascorbate can also catalyse ATRA reactions ${ }^{38}$. Though the last finding seemed reassuring, we anticipated that the "dye"-BODIPY dyads might perform differently in ATRA reactions due to the different mechanism of the triplet state formation. Indeed, it was shown, that the quantum yields of the triplet excited state formation in various "dye"-BODIPY dyads are largely determined by the energy of ${ }^{1} \mathrm{CS}$, which in turn depends on the polarity of the solvent. Thereby, any factors, which make up the reaction microenvironment, e.g., substrates, solvent mixtures and additives can potentially affect the efficiency of photocatalysis.

We started the investigation with the reaction between 5-hexen-1-ol (2) and diethyl bromomalonate (Scheme 1), and have chosen antracenyl-BODIPY (1a) and 9methylantracenyl-BODIPY (1) $)$ as the catalysts, due to the high quantum yields of the triplet excited state formation ( $\Phi_{\mathrm{T}}=0.93$ and 0.90 in acetonitrile, AcCN, respectfully) and quite high reduction potentials ([BODIPY]/[BODIPY] - = $1.01 \mathrm{~V}$ vs SCE) ${ }^{33}$. All reactions were performed in deoxygenated solutions under Ar, using $350 \mathrm{~nm}$ excitation light source, which selectively exited anthracene unit in the dyads $\mathbf{1 a}$ and $\mathbf{1 b}$. As the solvents, we have chosen $N, N$-dimethylformamide (DMF), dimethyl sulfoxide (DMSO) and AcCN, since the triplet excited states in the dyads $\mathbf{1 a}$ and $\mathbf{1 b}$ form with the highest efficiency in polar solvents ${ }^{33}$. No product 12 formation was observed when the reaction was performed in $\mathrm{DMF} / \mathrm{H}_{2} \mathrm{O}, 1: 1$ mixture, using triethylamine or 4-methoxy- $N, N$-diphenylaniline as sacrificial reductants, however the product was obtained with high yield of $87 \%$ when sodium ascorbate was used (Table 1, entry 1). Since we noticed a sufficient aggregation of the catalyst upon addition of water to the reaction mixture, the amount of water was reduced to solvent/water, 3:1 ratio. In $\mathrm{DMF} / \mathrm{H}_{2} \mathrm{O}, 3: 1$ mixture the product was formed with $86 \%$ yield (Table 1 , entry 3); quite good yield of $66 \%$ was obtained in DMSO $/ \mathrm{H}_{2} \mathrm{O}, 3: 1$ (Table 1, entry 4); and almost quantitative yield of $96 \%$ was obtained in $\mathrm{AcCN} / \mathrm{H}_{2} \mathrm{O}, 3: 1$ mixture (Table 1 , entry 5). Our attempts to improve the yield in $\mathrm{DMSO} / \mathrm{H}_{2} \mathrm{O}$, $3: 1$ by varying the reaction time were unsuccessful (Table S1, SI). In fact, the highest yield of $66 \%$ was obtained, when the reaction proceeded for $24 \mathrm{~h}$; and the yield decreased to $57 \%$ and $48 \%$ in the case of longer ( $30 \mathrm{~h}$ ) or shorter (18 h) reaction time, respectfully. In principle, these results were not surprising, since we anticipated that the yield of the product should depend on the solvent polarity. To get more insights on our observations, we measured the quantum yields of the triplet excited state formation for the dyad $\mathbf{1}$ in
Scheme 1. ATRA reactions between diethyl bromomalonate and various olefins

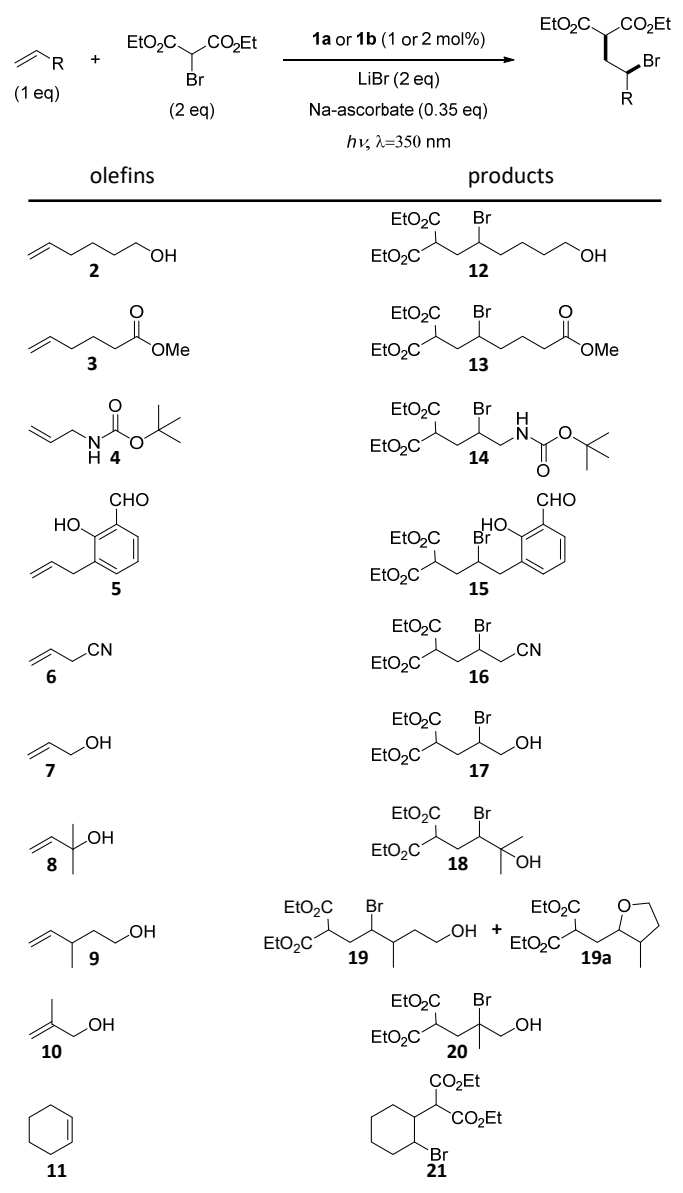

$\mathrm{DMF} / \mathrm{H}_{2} \mathrm{O}, \mathrm{AcCN} / \mathrm{H}_{2} \mathrm{O}$, and DMSO $/ \mathrm{H}_{2} \mathrm{O}, 3: 1$, and for all solvent mixtures the obtained values were about the same and equal to $\Phi_{\mathrm{T}}>0.90(\mathrm{SI})$. These results do not explain why in DMSO $/ \mathrm{H}_{2} \mathrm{O}$ mixture the yield of the product is lower. Probably, other factors play a crucial role in this case, and more mechanistic studies are required to shed light onto this issue. We then performed the reaction in $\mathrm{AcCN} / \mathrm{H}_{2} \mathrm{O}, 3: 1$ without the addition of $\mathrm{LiBr}$ to check whether it affects the reaction efficiency (Table S2, SI). The obtained yield of product 12 was c.a. 2 times lower, than for the case when LiBr was present in the reaction mixture. This observation is in the agreement with Stephenson's hypothesis, that the addition of Lewis acids facilitates the carbon-halogen bond breakage and the formation of radicals in ATRA reactions ${ }^{39}$. Next, we studied the scope of the reaction in application to various functionalized alkenes (Scheme 1, Table 1). The reaction between bromomalonate and terminal alkenes proceeded well in the presence of hydroxy-, aldehyde, cyano-, alkoxycarbonyl- and protected amino groups. As regards solvents, the best yields were obtained in $\mathrm{AcCN} / \mathrm{H}_{2} \mathrm{O}, 3: 1$ mixture, as compared to DMF $/ \mathrm{H}_{2} \mathrm{O}, 1: 1$ and $\mathrm{DMSO} / \mathrm{H}_{2} \mathrm{O}, 3: 1$ (Table 1, entry 9 vs. 10 vs. 11 ; entry 12 vs. 13 vs. 14). In addition, in DMF $/ \mathrm{H}_{2} \mathrm{O}$ we detected the formation of the oxidized byproducts in some cases (Table S1, SI), and in the case of DMSO/ $\mathrm{H}_{2} \mathrm{O}$ - the formation of higher amount of debrominated malonic ester. This trend is similar to what 
Table 1. ATRA reactions of various olefins under different conditions

\begin{tabular}{|c|c|c|c|c|c|c|}
\hline$\#$ & olefin & product & solvent & $\begin{array}{l}\text { cat./ } \\
\text { load }\end{array}$ & time & yield \\
\hline 1 & 2 & 12 & $\begin{array}{c}\mathrm{DMF} / \mathrm{H}_{2} \mathrm{O} \\
1: 1\end{array}$ & $\begin{array}{c}\mathbf{1 a}, \\
1 \mathrm{~mol} \%\end{array}$ & $24 \mathrm{~h}$ & $87 \%$ \\
\hline 2 & 2 & 12 & $\begin{array}{c}\mathrm{DMF} / \mathrm{H}_{2} \mathrm{O} \\
1: 1\end{array}$ & $\begin{array}{c}\mathbf{1 b}, \\
1 \mathrm{~mol} \%\end{array}$ & $24 \mathrm{~h}$ & $88 \%$ \\
\hline 3 & 2 & 12 & $\begin{array}{c}\mathrm{DMF} / \mathrm{H}_{2} \mathrm{O} \\
3: 1\end{array}$ & $\begin{array}{c}\mathbf{1 b}, \\
1 \mathrm{~mol} \%\end{array}$ & $24 \mathrm{~h}$ & $86 \%$ \\
\hline 4 & 2 & 12 & $\begin{array}{c}\mathrm{DMSO} / \mathrm{H}_{2} \mathrm{O} \\
3: 1\end{array}$ & $\begin{array}{c}\mathbf{1 a}, \\
1 \mathrm{~mol} \%\end{array}$ & $24 \mathrm{~h}$ & $66 \%$ \\
\hline 5 & 2 & 12 & $\begin{array}{c}\mathrm{AcCN} / \mathrm{H}_{2} \mathrm{O} \\
3: 1\end{array}$ & $\begin{array}{c}\mathbf{1 a}, \\
1 \mathrm{~mol} \%\end{array}$ & $24 \mathrm{~h}$ & $96 \%$ \\
\hline 6 & 3 & 13 & $\begin{array}{c}\mathrm{AcCN} / \mathrm{H}_{2} \mathrm{O} \\
3: 1\end{array}$ & $\begin{array}{c}\mathbf{1 a}, \\
1 \mathrm{~mol} \%\end{array}$ & $24 \mathrm{~h}$ & $99 \%$ \\
\hline 7 & 3 & 13 & $\begin{array}{c}\mathrm{AcCN} / \mathrm{H}_{2} \mathrm{O} \\
3: 1\end{array}$ & $\begin{array}{c}\mathbf{1 b}, \\
1 \mathrm{~mol} \%\end{array}$ & $24 \mathrm{~h}$ & $99 \%$ \\
\hline 8 & 4 & 14 & $\begin{array}{c}\mathrm{AcCN} / \mathrm{H}_{2} \mathrm{O} \\
3: 1\end{array}$ & $\begin{array}{c}\mathbf{1 b}, \\
2 \mathrm{~mol} \%\end{array}$ & $48 \mathrm{~h}$ & $94 \%$ \\
\hline 9 & 4 & 14 & $\begin{array}{c}\mathrm{DMF} / \mathrm{H}_{2} \mathrm{O} \\
1: 1\end{array}$ & $\begin{array}{c}\mathbf{1 b}, \\
2 \mathrm{~mol} \%\end{array}$ & $48 \mathrm{~h}$ & $90 \%$ \\
\hline 10 & 4 & 14 & $\begin{array}{c}\text { DMSO } / \mathrm{H}_{2} \mathrm{O} \\
3: 1\end{array}$ & $\begin{array}{c}\mathbf{1 a}, \\
1 \mathrm{~mol} \%\end{array}$ & $24 \mathrm{~h}$ & $15 \%$ \\
\hline 11 & 5 & 15 & $\begin{array}{c}\mathrm{AcCN} / \mathrm{H}_{2} \mathrm{O} \\
3: 1\end{array}$ & $\begin{array}{c}\mathbf{1 a}, \\
2 \mathrm{~mol} \%\end{array}$ & $48 \mathrm{~h}$ & $40 \%$ \\
\hline 12 & 5 & 15 & $\begin{array}{c}\mathrm{DMF} / \mathrm{H}_{2} \mathrm{O} \\
1: 1\end{array}$ & $\begin{array}{c}\mathbf{1 b}, \\
2 \mathrm{~mol} \%\end{array}$ & $48 \mathrm{~h}$ & $19 \%$ \\
\hline 13 & 5 & 15 & $\begin{array}{c}\text { DMSO } / \mathrm{H}_{2} \mathrm{O} \\
3: 1\end{array}$ & $\begin{array}{c}\mathbf{1 a}, \\
2 \mathrm{~mol} \%\end{array}$ & $48 \mathrm{~h}$ & $0 \%$ \\
\hline 14 & 6 & 16 & $\begin{array}{c}\mathrm{AcCN} / \mathrm{H}_{2} \mathrm{O} \\
3: 1\end{array}$ & $\begin{array}{c}\mathbf{1 a}, \\
1 \mathrm{~mol} \%\end{array}$ & $48 \mathrm{~h}$ & $15 \%$ \\
\hline 15 & 7 & 17 & $\begin{array}{c}\mathrm{AcCN} / \mathrm{H}_{2} \mathrm{O} \\
3: 1\end{array}$ & $\begin{array}{c}\text { 1a, } \\
2 \mathrm{~mol} \%\end{array}$ & $48 \mathrm{~h}$ & $62 \%$ \\
\hline 16 & 8 & 18 & $\begin{array}{c}\mathrm{AcCN} / \mathrm{H}_{2} \mathrm{O} \\
3: 1\end{array}$ & $\begin{array}{c}\mathbf{1 a}, \\
2 \mathrm{~mol} \%\end{array}$ & $72 \mathrm{~h}$ & $56 \%$ \\
\hline 17 & 9 & $19+19 a$ & $\begin{array}{c}\mathrm{AcCN} / \mathrm{H}_{2} \mathrm{O} \\
3: 1\end{array}$ & $\begin{array}{c}\mathbf{1 b}, \\
2 \mathrm{~mol} \%\end{array}$ & $48 \mathrm{~h}$ & $46 \%$ \\
\hline 18 & 10 & 20 & $\begin{array}{c}\mathrm{AcCN} / \mathrm{H}_{2} \mathrm{O} \\
3: 1\end{array}$ & $\begin{array}{c}\text { 1a, } \\
2 \mathrm{~mol} \%\end{array}$ & $48 \mathrm{~h}$ & $82 \%$ \\
\hline 19 & 11 & 21 & $\begin{array}{c}\mathrm{AcCN} / \mathrm{H}_{2} \mathrm{O} \\
3: 1\end{array}$ & $\begin{array}{c}\mathbf{1 a}, \\
2 \mathrm{~mol} \%\end{array}$ & $48 \mathrm{~h}$ & $10 \%$ \\
\hline
\end{tabular}

we observed initially for the reaction between 5-hexen-1-ol and diethyl bromomalonate. In respect of alkene substrates, the reaction proceeded well with terminal alkenes, but resulted in poor yields with secondary alkenes, e.g., only $10 \%$ yield was obtained for cyclohexene (Table 1, entry 19). For the terminal alkenes, almost quantitative yields were obtained when the functional groups were distant from the alkene fragment (Table 1, entries 5, 6). The presence of functional groups and/or alkyl substituents in the vicinity of the alkene resulted in lower, yet good yields. In addition, longer reaction time was required in the case of bulky substrates.
We assume, that in this case both, steric and electronic factors come to interplay. Thereby, the presence of highly electron withdrawing cyano- substituent at $\alpha$-position to alkene group led to a moderate $15 \%$ yield of the product (Table 1, entry 14). For the substrate 7 with less electron withdrawing hydroxy group at $\alpha$ - position, the yield was $62 \%$ (Table 1, entry 15), and for the substrate 5 with electron withdrawing aryl substituent at $\alpha$ - position, $40 \%$ yield was obtained (Table 1 entry 11). Methyl groups at $\alpha$ - position to the alkene fragment in substrates 8 and $\mathbf{9}$ led to $56 \%$ and $46 \%$ yields respectively (Table 1 , entries 16,17 ). Interestingly, a high yield of $82 \%$ was obtained for the substrate $\mathbf{1 0}$, despite the presence of electron withdrawing $\mathrm{OH}$ group at $\alpha$-position to alkene, and a methyl substituent at the double bond. This result can be attributed to the intermediate formation of stable tertiary radical or tertiary carbocation during the reaction, and is in a good agreement with the proposed mechanism.

We hypothesised, that the mechanism of the ATRA reaction, catalysed by the dyads $\mathbf{1 a}$ and $\mathbf{1 b}$ should be similar to the one proposed for diiodo-BODIPY38, except that the triplet excited state of BODIPY in the dyads $\mathbf{1 a}$ and $\mathbf{1 b}$ forms from the ${ }^{1} \mathrm{CS}$ state (Scheme 2). The participation of the triplet excited state in the reaction is supported by the fact, that the reaction did not proceed in the presence of oxygen, which quenches the triplet states. Thereby, upon excitation of anthracene unit at $\lambda_{\mathrm{ex}}=350 \mathrm{~nm}$, ultrafast energy transfer from ${ }^{\mathrm{S}}[\mathrm{Ant}]^{*}$ to ${ }^{\mathrm{S}}$ [BODIPY] ${ }^{*}$ occurs, which is followed by an electron transfer within the dyad $\mathbf{1 a}$ or $\mathbf{1 b}$, resulting in the formation of ${ }^{1} \mathrm{CS}$ state [Ant] ${ }^{\circ+}$ [BODIPY] ${ }^{\bullet}$. Then, ${ }^{\mathrm{T} 1}[\mathrm{BODIPY}]^{*}$ forms as a result of SOCT-ISC process. In principle, ${ }^{\mathrm{T} 1}[\mathrm{Ant}]^{*}$ could also form. However, as it was shown earlier for the dyad 1a, the majority of the triplet excitation energy is on BODIPY, and the contribution of ${ }^{\mathrm{T}}\left[{ }^{2} \mathrm{Ant}\right]^{*}$ is small. ${ }^{40}$ Single electron transfer (SET) from the sacrificial reductant - sodium ascorbate - converts the triplet excited state ${ }^{\text {T1 }}$ [BODIPY]* into radical-anion [BODIPY]*-, which has high enough reduction potential ([BODIPY]/[BODIPY] ${ }^{*}=-1.01 \mathrm{~V}$ vs SCE $)^{33}$ to convert bromomalonate into malonic radical. . Malonic radical further undergoes the addition to alkenes

\section{Scheme 2. Proposed mechanism for ATRA reaction cat- alysed by Ant-BODIPY dyad}

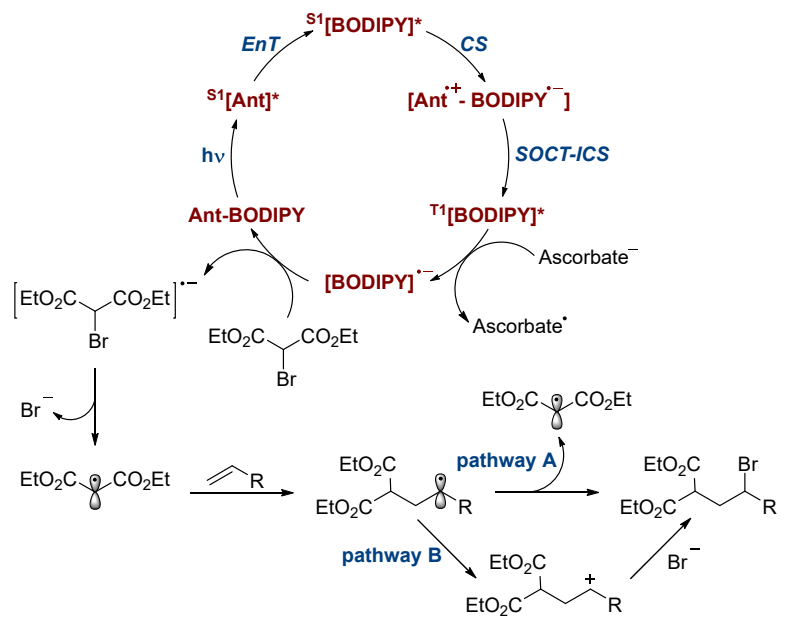


AUTHOR INFORMATION
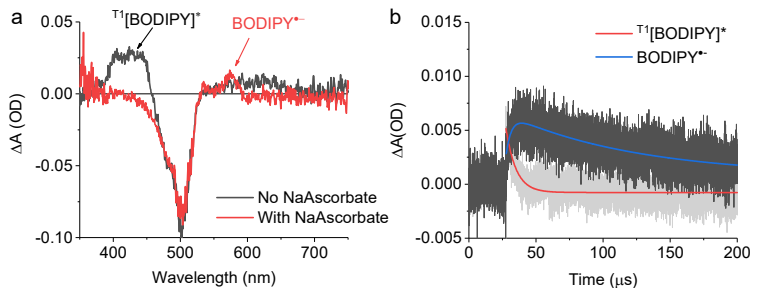

Figure 2. (a) Transient absorption spectra of $\mathbf{1 a}$ at $10 \mu$ s after the ns laser pulse $\left(\lambda_{\mathrm{ex}}=355 \mathrm{~nm}\right)$ in $\mathrm{AcCN} / \mathrm{H}_{2} \mathrm{O}=3: 1$ in the presence and absence of sodium ascorbate. (b) Decay kinetics of 1a in $\mathrm{AcCN} / \mathrm{H}_{2} \mathrm{O}=3: 1$ in the presence of sodium ascorbate at the T1 [BODIPY]* absorption band (430 $\mathrm{nm}$ ) and the [BODIPY] ${ }^{*}$ absorption band $(570 \mathrm{~nm})$.

with the formation of the corresponding radical. The ATRA product could form through the abstraction of halogen from another equivalent of bromomalonate (radical propagation pathway, A), or through single-electron oxidation to carbocation with subsequent trapping by bromine-anion (radical-polar crossover pathway, B), as proposed by Stephenson $^{37}$.

Hypothetically, the malonic radical could form through the SET from ${ }^{1} \mathrm{CS}$ state [Ant ${ }^{*+}$-BODIPY ${ }^{\bullet}$ ], followed by the reduction of $[\mathrm{Ant}]^{{ }^{+}}$unit with sodium ascorbate. However, transient absorption spectroscopy studies eliminated this possibility by showing that the lifetime of the ${ }^{1} \mathrm{CS}$ state is too short to undergo intermolecular reactions (more details in $\mathrm{SI}$ ), and further confirming that [BODIPY]-- is produced by the reduction of ${ }^{\mathrm{T}}$ [BODIPY] ${ }^{*}$ by sodium ascorbate (Fig. 2).

Finally, we confirmed that the ATRA reactions proceed with the same efficiency under visible light irradiation. Thereby, the reaction between diethyl bromomalonate and substrates 2 and 3 in $\mathrm{AcCN} / \mathrm{H}_{2} \mathrm{O}, 3: 1$ mixture, and using catalyst $\mathbf{1 b}$ and $470 \mathrm{~nm}$ excitation light source led to the products 12 and 13 with $98 \%$ and $99 \%$ yields respectively (Table $\mathrm{S} 3, \mathrm{SI})$. In this case a BODIPY unit was selectively excited at $\lambda_{\mathrm{ex}}=470 \mathrm{~nm}$ to produce ${ }^{\mathrm{S}}\left[\right.$ [BODIPY] ${ }^{*}$. The remaining steps of the mechanism are analogous to the described above for $350 \mathrm{~nm}$ excitation.

\section{CONCLUSIONS}

In conclusion, we demonstrated that BODIPY-based donor-acceptor dyads can efficiently catalyse light-driven ATRA reactions. The dyads can be excited with UV and visible light. Given the ease of the synthesis, availability of the synthetic precursors and readily tunable photophysical and redox properties, these dyads can become a new inexpensive environmentally friendly alternative to the classical organometallic photocatalysts.

\section{ASSOCIATED CONTENT}

Supporting Information. Experimental details and spectral characterizations of the catalysts and obtained compounds are available in the Supporting Information (SI).

\section{Corresponding Authors}

Tatiana V. Esipova - Department of Chemistry and Biochemistry, Loyola University Chicago, Chicago, IL 60660, USA.Email: tesipova@luc.edu

Tomoyasu Mani - Department of Chemistry, University of Connecticut, Storrs, CT 06269-3060, USA. E-mail: tomoyasu.mani@uconn.edu

\section{Authors}

Sara Abuhadba - Department of Chemistry and Biochemistry, Loyola University Chicago, Chicago, IL 60660, USA.

Miu Tsuji - Department of Chemistry, University of Connecticut, Storrs, CT 06269-3060, USA.

Notes

The Authors declare no competing financial interest

\section{ACKNOWLEDGMENT}

This work is supported by start-up funds from Loyola University Chicago (TVE) and by start-up funds from University of Connecticut (TM). We are grateful to Mr. Ronald Paolella (The Southern New England Ultraviolet Co. Int.) for kindly providing the RPR-100 photochemical reactor for our research.

\section{REFERENCES}

1. Ischay, M. A.; Anzovino, M. E.; Du, J.; Yoon, T. P., Efficient Visible Light Photocatalysis of [2+2] Enone Cycloadditions. Journal of the American Chemical Society 2008, 130 (39), 12886-12887.

2. Nicewicz, D. A.; MacMillan, D. W. C., Merging Photoredox Catalysis with Organocatalysis: The Direct Asymmetric Alkylation of Aldehydes. Science 2008, 322 (5898), 77-80.

3. Narayanam, J. M. R.; Tucker, J. W.; Stephenson, C. R. J., Electron-Transfer Photoredox Catalysis: Development of a TinFree Reductive Dehalogenation Reaction. Journal of the American Chemical Society 2009, 131 (25), 8756-8757.

4. Narayanam, J. M. R.; Stephenson, C. R. J., Visible light photoredox catalysis: applications in organic synthesis. Chemical Society Reviews 2011, 40 (1), 102-113.

5. Prier, C. K.; Rankic, D. A.; MacMillan, D. W. C., Visible Light Photoredox Catalysis with Transition Metal Complexes: Applications in Organic Synthesis. Chemical Reviews 2013, 113 (7), 5322-5363.

6. To, W.-P.; Liu, Y.; Lau, T.-C.; Che, C.-M., A Robust Palladium(II)-Porphyrin Complex as Catalyst for Visible Light Induced Oxidative $\mathrm{C}-\mathrm{H}$ Functionalization. Chemistry - A European Journal 2013, 19 (18), 5654-5664.

7. Stevenson, S. M.; Shores, M. P.; Ferreira, E. M., Photooxidizing Chromium Catalysts for Promoting Radical Cation Cycloadditions. Angewandte Chemie International Edition 2015, 54 (22), 6506-6510.

8. Gualandi, A.; Marchini, M.; Mengozzi, L.; Natali, M.; Lucarini, M.; Ceroni, P.; Cozzi, P. G., Organocatalytic Enantioselective Alkylation of Aldehydes with [Fe(bpy)3]Br2 Catalyst and Visible Light. ACS Catalysis 2015, 5 (10), 5927-5931.

9. Pirtsch, M.; Paria, S.; Matsuno, T.; Isobe, H.; Reiser, O., [Cu(dap)2Cl] As an Efficient Visible-Light-Driven Photoredox Catalyst in Carbon-Carbon Bond-Forming Reactions. Chemistry - A European Journal 2012, 18 (24), 7336-7340. 
10. Reiser, 0., Shining Light on Copper: Unique Opportunities for Visible-Light-Catalyzed Atom Transfer Radical Addition Reactions and Related Processes. Accounts of Chemical Research 2016, 49 (9), 1990-1996.

11. Hernandez-Perez, A. C.; Collins, S. K., Heteroleptic CuBased Sensitizers in Photoredox Catalysis. Accounts of Chemical Research 2016, 49 (8), 1557-1565.

12. Rybicka-Jasińska, K.; Shan, W.; Zawada, K.; Kadish, K. M.; Gryko, D., Porphyrins as Photoredox Catalysts: Experimental and Theoretical Studies. Journal of the American Chemical Society 2016, 138 (47), 15451-15458.

13. Zhang, Y.; Petersen, J. L.; Milsmann, C., A Luminescent Zirconium(IV) Complex as a Molecular Photosensitizer for Visible Light Photoredox Catalysis. Journal of the American Chemical Society 2016, 138 (40), 13115-13118.

14. Büldt, L. A.; Guo, X.; Prescimone, A.; Wenger, O. S., A Molybdenum(0) Isocyanide Analogue of Ru(2,2'-Bipyridine)32+: A Strong Reductant for Photoredox Catalysis. Angewandte Chemie International Edition 2016, 55 (37), 11247-11250.

15. Mandal, T.; Das, S.; De Sarkar, S., Nickel(II) Tetraphenylporphyrin as an Efficient Photocatalyst Featuring Visible Light Promoted Dual Redox Activities. Advanced Synthesis \& Catalysis 2019, 361 (13), 3200-3209.

16. Pitre, S. P.; McTiernan, C. D.; Ismaili, H.; Scaiano, J. C., Mechanistic Insights and Kinetic Analysis for the Oxidative Hydroxylation of Arylboronic Acids by Visible Light Photoredox Catalysis: A Metal-Free Alternative. Journal of the American Chemical Society 2013, 135 (36), 13286-13289.

17. Li, W.; Li, L.; Xiao, H.; Qi, R.; Huang, Y.; Xie, Z.; Jing, X.; Zhang, H., Iodo-BODIPY: a visible-light-driven, highly efficient and photostable metal-free organic photocatalyst. RSC Advances 2013, 3 (32), 13417-13421.

18. Ohkubo, K.; Fujimoto, A.; Fukuzumi, S., Metal-free oxygenation of cyclohexane with oxygen catalyzed by 9-mesityl10-methylacridinium and hydrogen chloride under visible light irradiation. Chemical Communications 2011, 47 (30), 8515-8517.

19. Huang, L.; Zhao, J.; Guo, S.; Zhang, C.; Ma, J., Bodipy Derivatives as Organic Triplet Photosensitizers for Aerobic Photoorganocatalytic Oxidative Coupling of Amines and Photooxidation of Dihydroxylnaphthalenes. The Journal of Organic Chemistry 2013, 78 (11), 5627-5637.

20. Wang, L.; Cao, J.; Wang, J.-w.; Chen, Q.; Cui, A.-j.; He, M.y., Facile synthesis of dimeric BODIPY and its catalytic activity for sulfide oxidation under visible light. RSC Advances 2014, 4 (28), 14786-14790.

21. Pitre, S. P.; McTiernan, C. D.; Scaiano, J. C., Library of Cationic Organic Dyes for Visible-Light-Driven Photoredox Transformations. ACS Omega 2016, 1 (1), 66-76.

22. Pitre, S. P.; McTiernan, C. D.; Ismaili, H.; Scaiano, J. C., Metal-Free Photocatalytic Radical Trifluoromethylation Utilizing Methylene Blue and Visible Light Irradiation. ACS Catalysis 2014, 4 (8), 2530-2535.

23. Neumann, M.; Füldner, S.; König, B.; Zeitler, K., MetalFree, Cooperative Asymmetric Organophotoredox Catalysis with Visible Light. Angewandte Chemie International Edition 2011, 50 (4), 951-954.

24. Hari, D. P.; Schroll, P.; König, B., Metal-Free, VisibleLight-Mediated Direct C-H Arylation of Heteroarenes with Aryl Diazonium Salts. Journal of the American Chemical Society 2012, 134 (6), 2958-2961.

25. Riener, M.; Nicewicz, D. A., Synthesis of cyclobutane lignans via an organic single electron oxidant-electron relay system. Chemical Science 2013, 4 (6), 2625-2629.

26. Huang, L.; Zhao, J., Iodo-Bodipys as visible-lightabsorbing dual-functional photoredox catalysts for preparation of highly functionalized organic compounds by formation of $\mathrm{C}-\mathrm{C}$ bonds via reductive and oxidative quenching catalytic mechanisms. RSC Advances 2013, 3 (45), 23377-23388.
27. Romero, N. A.; Nicewicz, D. A., Mechanistic Insight into the Photoredox Catalysis of Anti-Markovnikov Alkene Hydrofunctionalization Reactions. Journal of the American Chemical Society 2014, 136 (49), 17024-17035.

28. Wilger, D. J.; Grandjean, J.-M. M.; Lammert, T. R.; Nicewicz, D. A., The direct anti-Markovnikov addition of mineral acids to styrenes. Nature Chemistry 2014, 6 (8), 720-726.

29. Hamilton, D. S.; Nicewicz, D. A., Direct Catalytic AntiMarkovnikov Hydroetherification of Alkenols. Journal of the American Chemical Society 2012, 134 (45), 18577-18580.

30. Grandjean, J.-M. M.; Nicewicz, D. A., Synthesis of Highly Substituted Tetrahydrofurans by Catalytic Polar-RadicalCrossover Cycloadditions of Alkenes and Alkenols. Angewandte Chemie International Edition 2013, 52 (14), 3967-3971.

31. Juris, A.; Balzani, V.; Belser, P.; von Zelewsky, A., Characterization of the Excited State Properties of Some New Photosensitizers of the Ruthenium (Polypyridine) Family. Helvetica Chimica Acta 1981, 64 (7), 2175-2182.

32. Romero, N. A.; Nicewicz, D. A., Organic Photoredox Catalysis. Chemical Reviews 2016, 116 (17), 10075-10166.

33. Buck, J. T.; Boudreau, A. M.; DeCarmine, A.; Wilson, R. W.; Hampsey, J.; Mani, T., Spin-Allowed Transitions Control the Formation of Triplet Excited States in Orthogonal Donor-Acceptor Dyads. Chem 2019, 5 (1), 138-155.

34. Okada, T.; Karaki, I.; Matsuzawa, E.; Mataga, N.; Sakata, Y.; Misumi, S., Ultrafast Intersystem Crossing in Some Intramolecular Heteroexcimers. J Phys Chem-Us 1981, 85 (26), 3957-3960.

35. vanWilligen, H.; Jones, G.; Farahat, M. S., Time-resolved EPR study of photoexcited triplet-state formation in electrondonor-substituted acridinium ions. J Phys Chem-Us 1996, 100 (9), 3312-3316.

36. Dance, Z. E. X.; Mi, Q. X.; McCamant, D. W.; Ahrens, M. J.; Ratner, M. A.; Wasielewski, M. R., Time-resolved EPR studies of photogenerated radical ion pairs separated by $p$-phenylene oligomers and of triplet states resulting from charge recombination. J Phys Chem B 2006, 110 (50), 25163-25173.

37. Wallentin, C.-J.; Nguyen, J. D.; Finkbeiner, P.; Stephenson, C. R. J., Visible Light-Mediated Atom Transfer Radical Addition via Oxidative and Reductive Quenching of Photocatalysts. Journal of the American Chemical Society 2012, 134 (21), 88758884.

38. Magagnano, G.; Gualandi, A.; Marchini, M.; Mengozzi, L.; Ceroni, P.; Cozzi, P. G., Photocatalytic ATRA reaction promoted by iodo-Bodipy and sodium ascorbate. Chemical Communications 2017, 53 (10), 1591-1594.

39. Nguyen, J. D.; Tucker, J. W.; Konieczynska, M. D.; Stephenson, C. R. J., Intermolecular Atom Transfer Radical Addition to Olefins Mediated by Oxidative Quenching of Photoredox Catalysts. Journal of the American Chemical Society 2011, 133 (12), 4160-4163.

40. Wang, Z.; Sukhanov, A. A.; Toffoletti, A.; Sadiq, F.; Zhao, J.; Barbon, A.; Voronkova, V. K.; Dick, B., Insights into the Efficient Intersystem Crossing of Bodipy-Anthracene Compact Dyads with Steady-State and Time-Resolved Optical/Magnetic Spectroscopies and Observation of the Delayed Fluorescence. The Journal of Physical Chemistry C 2019, 123 (1), 265-274. 